\title{
Metabolic-related markers and inflammatory factors as predictors of dyslipidemia among urban Han Chinese adults
}

Ying Lian ${ }^{1,2}$, Lingling Xie ${ }^{3}$, Yafei Liu ${ }^{1,2}$ and Fang Tang ${ }^{1,2^{*}}$ (1)

\begin{abstract}
Background: Metabolic-related markers and inflammatory factors have been proved to be associated with increased risk of dyslipidemia. Elucidating the mechanisms underlying these associations might provide an important perspective for the prevention of dyslipidemia. In the present study, we aimed to explore the effect of metabolic-related markers on dyslipidemia, and to assess what extent inflammation mediating these associations.

Methods: A total of 25,130 participants without dyslipidemia at baseline were included in the present study during 2010-2015. A partial least squares path model was used to explore possible pathways from metabolic-related markers to dyslipidemia, and the mediation role of inflammation.

Results: Lipid metabolism factor, blood pressure factor, obesity condition factor, glucose metabolism factor, renal function factor and lifestyle factor had diverse impact on development of dyslipidemia, directly and (or) indirectly. Partial least squares path analysis revealed that the determination coefficient of the model $\left(R^{2}\right)$ was 0.52 . Lipid metabolism factor, obesity condition factor, and glucose metabolism factor had both direct and indirect effect on dyslipidemia through inflammatory factor. Lipid metabolism factor was the most important risk factor $(\beta=0.68)$ in the prediction of dyslipidemia, followed by obesity condition factor $(\beta=0.06)$ and glucose metabolism factor $(\beta=0.03)$.

Conclusions: Metabolic-related markers are strong risk factors for dyslipidemia. Inflammatory factors have significant mediating effect on these relationships. These findings suggested that comprehensive intervention strategies on metabolic biomarkers and inflammatory factors should be taken into consideration in prevention and treatment of dyslipidemia.
\end{abstract}

Keywords: Metabolic-related markers, Inflammation, Dyslipidemia, Mediation, Cohort study

\section{Background}

Dyslipidemia has become an emerging epidemic worldwide [1, 2]. Based on a report from American College of Cardiology, about 39\% of the global population has elevated cholesterol, and more than one-half of those individuals live in developed countries [3]. Epidemiological studies conducted in China showed that the prevalence of

\footnotetext{
* Correspondence: tangfangsdu@126.com

${ }^{1}$ Center for Data Science in Health and Medicine, Shandong Provincial

Qianfoshan Hospital, The First Affiliated Hospital of Shandong First Medical

University, Jingshi Road 16766, Jinan 250014, China

${ }^{2}$ Shandong Provincial Qianfoshan Hospital Affiliated to Shandong University, Jinan, China

Full list of author information is available at the end of the article
}

dyslipidemia significantly increased in recent years $[4,5]$. The Global Burden of Disease, Injuries, and Risk Factor study indicated that during the past decades worldwide morbidity and mortality attributable to dyslipidemia have increased by 26.9 and $28.0 \%$, respectively [6].

Metabolic-related risk factors such as glucose level and hypertension have been proved to be associated with dyslipidemia [7, 8]. Most of these factors reflect different metabolic pathways that may be involved in the pathogenesis of dyslipidemia. However, previous studies mainly focused on estimating the associations between risk factors and dyslipidemia or improving the prediction of dyslipidemia using these biomarkers [9-12]. Few

(c) The Author(s). 2019 Open Access This article is distributed under the terms of the Creative Commons Attribution 4.0 International License (http://creativecommons.org/licenses/by/4.0/), which permits unrestricted use, distribution, and 
studies have attempted to evaluate a comprehensive panel of multiple metabolic-related factors representing distinct pathogenetic pathways for predicting the development of dyslipidemia. Elucidating the mechanisms underlying the associations between biomarkers and dyslipidemia by pathway analysis might provide a novel perspective for the research of dyslipidemia.

Inflammation is receiving increasingly attention for its potential role in the pathogenesis of metabolic disorders including dyslipidemia [13-15]. Individuals with dyslipidemia have higher levels of inflammatory biochemical markers than those without dyslipidemia [15]. Most of available studies implicating inflammation are based on measurements of pro-inflammation cytokines and chemokines, which are limited for laboratory methods, especially in a large sample of population. Routine check-up biomarkers such as white blood cell count (WBC), $\gamma$-glutamyltransferase (GGT) are well-recognized indicators of inflammation [16, 17]. Moreover, several studies have found the mediating role of systemic inflammation in the effect of metabolic-related factors on metabolic diseases such as hypertension and subclinical atherosclerosis $[18,19]$. Therefore, we hypothesized that inflammation may play a mediation role in development of dyslipidemia, mediating at least part of the associations between metabolic-related markers and dyslipidemia.

In the present study, data from a perspective cohort of Chinese routine health check-up population were used to explore the effect of metabolic-related markers on dyslipidemia, and the mediation role of inflammatory factors among this relationship.

\section{Methods}

\section{Study population}

The large-scale perspective cohort study was set up in 2010 based on the routine health check-up system in the Center for Health Management of Shandong Provincial Qianfoshan Hospital. Participants free of dyslipidemia, diabetes, cardiovascular disease, hepatosis, renal dysfunction, and hypothyroidism at baseline were recruited, and followed up for dyslipidemia with well-designed clinical and laboratory examinations. The cohort was selected from participants who took the first health check in 2010, 2011, 2012, 2013 or 2014 respectively and at least took health check-up 2 times in the 5-years follow-up. A total of 25,130 participants were included in the analyses.

\section{Measurements of anthropometric and lifestyle variables}

Anthropometric data were collected following a standardized procedure. Height and weight were measured while participants wore light clothes without shoes. The body mass index (BMI) was calculated as weight $(\mathrm{kg}) \mathrm{di}$ vided by height squared $\left(\mathrm{m}^{2}\right)$. Smoking and drinking statuses were classified as "never", "former", or "current" according to self-reported questions.

\section{Measurements of biochemical biomarkers}

Venous blood samples were drawn after at least $12 \mathrm{~h}$ of fasting for laboratory tests. Systolic blood pressure (SBP) and diastolic blood pressure (DBP) were measured on the right arm of seated participants by a physician using Omron HEM-907 (Quick Medical) by the cuffoscillometric method. Blood biochemical biomarkers including white blood cell count (WBC), neutrophile granulocyte (NGC), monocyte count (MCC), triglyceride (TG), high-density lipoprotein cholesterol (HDLC), total cholesterol (TC), low-density lipoprotein cholesterol (LDL-C), $\gamma$-glutamyltransferase (GGT), fasting blood glucose (FBG), blood urea nitrogen (BUN) and Creatinine were tested in the national accredited laboratory in Shandong Provincial Qianfoshan Hospital following standard procedures.

\section{Definition of dyslipidemia}

Dyslipidemia was defined according to 2016 Chinese guideline for the management of dyslipidemia proposed by guideline revision National Expert Committee [2]. Dyslipidemia was diagnosed as TG $\geq 2.3 \mathrm{mmol} / \mathrm{L}(\geq 200$ $\mathrm{mg} / \mathrm{dl})$, and/ or LDL-C $\geq 4.1 \mathrm{mmol} / \mathrm{L}(\geq 160 \mathrm{mg} / \mathrm{dl})$, and or $\mathrm{TC} \geq 6.2 \mathrm{mmol} / \mathrm{L}(\geq 240 \mathrm{mg} / \mathrm{dl})$, and $/$ or HDL-C $\leq 1.0$ $\mathrm{mmol} / \mathrm{L}(\leq 40 \mathrm{mg} / \mathrm{dl})$ and/ or self-reported clinically diagnosed dyslipidemia.

\section{Statistical analyses}

The baseline characteristics of the sample by group were compared using $t$ tests for continuous variables, and $X^{2}$ tests for categorical variables. SPSS16.0 was used to run $t$ tests and $X^{2}$ tests. A partial least squares path model (PLSPM) was employed to explore possible pathways from metabolic-related markers to dyslipidemia. The PLSPM is a variance-based structural equation modeling, which allows for the construction of a path model between a set of latent variables (inner model), each of which being represented by a block of correlated measured or manifest variables (outer model) [20].

In this study, latent variables including lipid metabolism factor (LMF), blood pressure factor (BPF), obesity condition factor (OCF), glucose metabolism factor (GMF), renal function factor (RFF), lifestyle factor and inflammatory factor (IF) were measured at baseline. The latent variable of dyslipidemia with manifest variables of LDL-C, TC, TG and HDL-C were measured at the end of follow-up. This representation indicated that LMF could manifest as TG, LDL-C, TC and HDL-C at baseline. BPF loaded on both SBP and DBP. OCF loaded on BMI. GMF loaded on FBG. Lifestyle factor loaded on smoking status and drinking status. RFF loaded on BUN 
and Creatinine. And IF loaded on GGT, WBC, NGC and MCC. The total effect $(\beta)$ of each latent variable was the sum of direct and indirect effect on dyslipidemia. Lohmöller algorithm were used to estimate path coefficients and factor loadings [21]. Bootstrapping in PLS offers $t$ test statistics that confirm statistical significance [21, 22]. The SmartPLS 2.0 was used to build PLSPM [23].

\section{Results}

\section{Baseline characteristics}

A total of 25,130 participants with a mean age of $42.4 \pm$ 13.8 years were included in present study with 50,014 person-years of follow-up. Five thousand five hundred fiftyone participants developed dyslipidemia during 5-year follow-up. The total incidence density was $110.99 / 1000$ person-years (5551/50014 person-years). Table 1 shows the baseline characteristics by the incident dyslipidemia status (dyslipidemia and non-dyslipidemia). Males, elders, participants with higher proportion of current smoking status and drinking status, BMI, TG, TC, LDL-C, SBP, DBP, GGT,
NGC, MCC, WBC, FBG, BUN, Creatinine level and lower HDL-C level at baseline were likely to have new-onset dyslipidemia (Table 1).

\section{Pathway analysis using PLSPM}

Figure 1 shows the results from the final PLSPM that illustrated possible pathways of metabolic-related biomarkers on dyslipidemia. The determination coefficient of the model $\left(R^{2}\right)$ was 0.52 , indicating that seven latent variables explained $52 \%$ of the total variance and thus had an acceptable capacity in explanation of dyslipidemia.

In the outer model, the results showed that the manifest variable of baseline LDL-C was the most significant contributor in the formation of LMF (loading $=0.89$ ), followed by baseline TC (loading $=0.75$ ), baseline TG (loading= 0.72 ) and baseline HDL-C (loading $=-0.26$ ). SBP and DBP had positive effects on the block of BPF with loading 0.93 and 0.95. BUN and Creatinine had positive effects on the block of RFF with loading 0.68 and 0.91 . Smoking status and drinking status had positive effects on the block of

Table 1 Baseline characteristics of participants grouped by dyslipidemia

\begin{tabular}{|c|c|c|c|c|c|}
\hline Variables & Total & Dyslipidemia & Non-dyslipidemia & $\mathrm{t} / \mathrm{x}^{2}$ value & $P$ value \\
\hline Sex (males) & $13,315(53.0)$ & 3855 (69.4) & $9460(48.3)$ & 775.12 & $<0.01$ \\
\hline Age (years) & $42.4 \pm 13.8$ & $45.4 \pm 13.7$ & $41.6 \pm 13.7$ & -18.39 & $<0.01$ \\
\hline Smoking status & & & & 244.7 & $<0.01$ \\
\hline Never & $18,806(83.5)$ & 3485 (75.9) & $15,321(85.4)$ & & \\
\hline Former & $70(0.3)$ & $26(0.6)$ & $44(0.2)$ & & \\
\hline Current & 3654 (16.2) & $1083(23.5)$ & $2571(14.4)$ & & \\
\hline Drinking status & & & & 353.5 & $<0.01$ \\
\hline Never & $15,905(70.6)$ & $2734(59.5)$ & $13,171(73.4)$ & & \\
\hline Former & $25(0.1)$ & $14(0.3)$ & $11(0.1)$ & & \\
\hline Current & $6600(29.3)$ & $1846(40.2)$ & $4754(26.5)$ & & \\
\hline BMI $\left(\mathrm{kg} / \mathrm{m}^{2}\right)$ & $23.5 \pm 3.3$ & $24.9 \pm 3.1$ & $23.1 \pm 3.2$ & -37.07 & $<0.01$ \\
\hline $\mathrm{HDL}-\mathrm{C}(\mathrm{mmol} / \mathrm{L})$ & $1.6 \pm 0.3$ & $1.4 \pm 0.3$ & $1.6 \pm 0.3$ & 24.42 & $<0.01$ \\
\hline TG (mmol/L) & $1.0 \pm 0.3$ & $1.2 \pm 0.3$ & $0.9 \pm 0.3$ & -60.39 & $<0.01$ \\
\hline $\mathrm{TC}(\mathrm{mmol} / \mathrm{L})$ & $4.6 \pm 0.7$ & $4.9 \pm 0.7$ & $4.5 \pm 0.6$ & -38.21 & $<0.01$ \\
\hline LDL-C (mmol/L) & $2.6 \pm 0.6$ & $2.9 \pm 0.5$ & $2.5 \pm 0.5$ & -47.86 & $<0.01$ \\
\hline $\mathrm{SBP}(\mathrm{mmHg})$ & $124.7 \pm 17.5$ & $129.2 \pm 17.7$ & $123.5 \pm 17.2$ & -21.73 & $<0.01$ \\
\hline $\mathrm{DBP}(\mathrm{mmHg})$ & $78.2 \pm 11.5$ & $81.5 \pm 11.4$ & $77.3 \pm 11.4$ & -24.29 & $<0.01$ \\
\hline GGT (U/L) & $21.9 \pm 21.0$ & $28.5 \pm 29.7$ & $20.1 \pm 17.3$ & -26.64 & $<0.01$ \\
\hline $\operatorname{NGC}\left(10^{9} / L\right)$ & $3.4 \pm 1.1$ & $3.5 \pm 1.1$ & $3.3 \pm 1.1$ & -9.1 & $<0.01$ \\
\hline $\operatorname{MCC}\left(10^{9} / \mathrm{L}\right)$ & $0.3 \pm 0.1$ & $0.4 \pm 0.1$ & $0.3 \pm 0.1$ & -8.81 & $<0.01$ \\
\hline WBC $\left(10^{9} / L\right)$ & $6.1 \pm 1.4$ & $6.3 \pm 1.5$ & $6.0 \pm 1.4$ & -12.74 & $<0.01$ \\
\hline FBG (mmol/L) & $5.1 \pm 0.5$ & $5.2 \pm 0.6$ & $5.1 \pm 0.5$ & -20.52 & $<0.01$ \\
\hline Creatinine (umol/L) & $67.5 \pm 17.2$ & $70.4 \pm 16.4$ & $66.8 \pm 17.3$ & -12.44 & $<0.01$ \\
\hline BUN (mmol/L) & $4.8 \pm 1.3$ & $5.1 \pm 1.2$ & $4.7 \pm 1.3$ & -17.5 & $<0.01$ \\
\hline
\end{tabular}

$B M I$ Body mass index, $H D L-C$ high-density lipoprotein cholesterol, $T C$ total cholesterol, $T G$ triglyceride, $L D L-C$ low-density lipoprotein cholesterol, $S B P$ systolic blood pressure, $D B P$ diastolic blood pressure, GGT Y-glutamyltransferase, NGC neutrophile granulocyte, $M C C$ monocyte count, WBC white blood cell count, $F B G$ fasting blood glucose, BUN blood urea nitrogen 


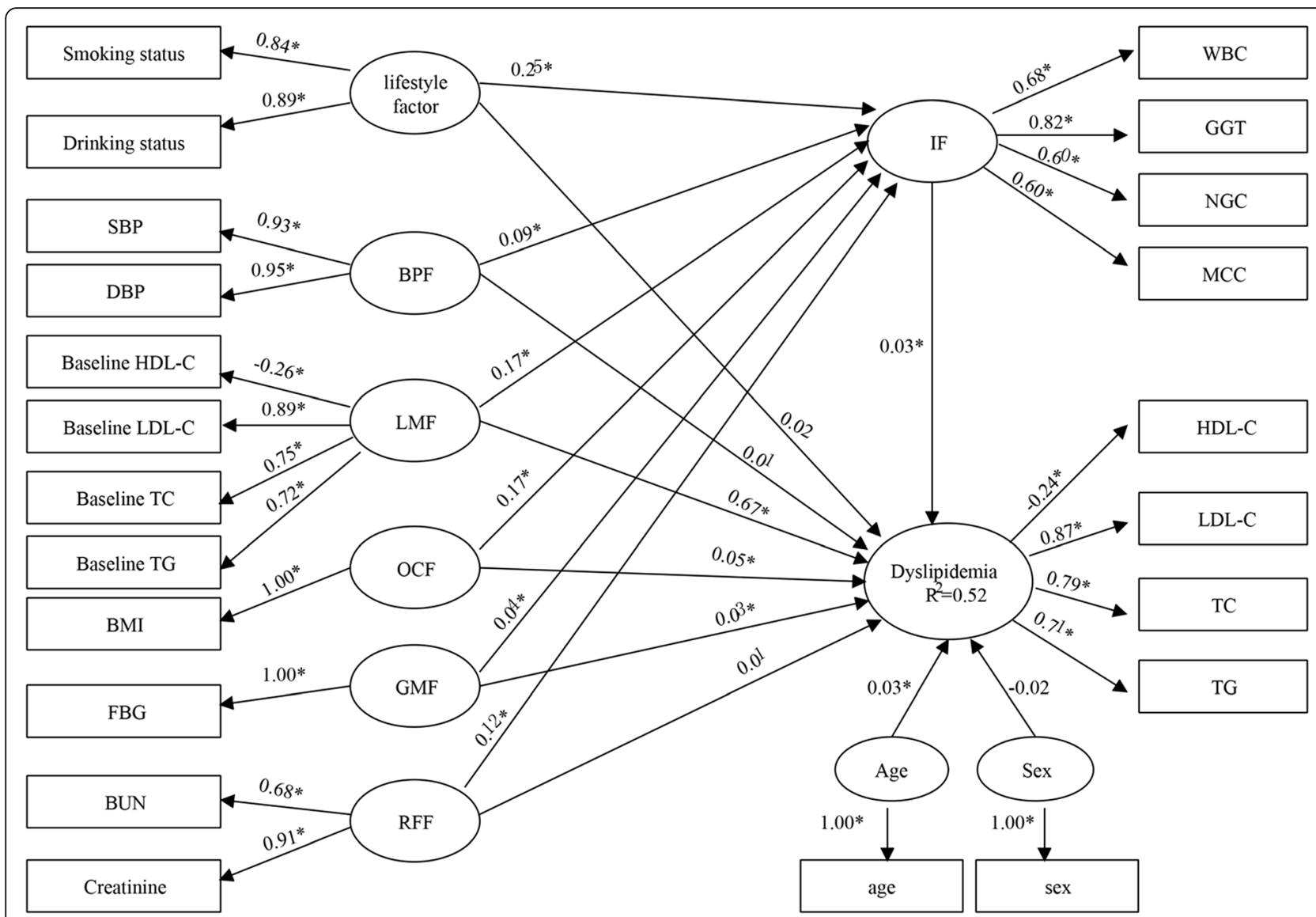

Fig. 1 The partial least squares path model for metabolic-related markers and inflammatory factors associated with dyslipidemia. ${ }^{*} P<0.05$

lifestyle factor with loading 0.84 and 0.89 . For the block of IF, GGT was the most important contributor (loading= 0.82 ), followed by WBC (loading $=0.68$ ), NGC (loading = 0.60 ) and MCC (loading = 0.60).

For the inner model, LMF, OCF and GMF all had direct effect as well as indirect effect on dyslipidemia through IF. However, BPF, RFF and lifestyle factor only had indirect effect on dyslipidemia through IF. LMF was the most important risk factor $[\beta=0.68$, including a direct effect of 0.67, and an indirect effect of $0.01(0.17 \times$ $0.03)]$ in the prediction of dyslipidemia, followed by OCF $[\beta=0.06$, including a direct effect: 0.05 , an indirect effect: $0.01(0.17 \times 0.03)]$ and GMF $[\beta=0.03$, including a direct effect: 0.03 , an indirect effect: $0.001(0.04 \times 0.03)$ ] (Table 2).

\section{Discussion}

In the present study, we explored the effect of metabolicrelated markers on dyslipidemia and the mediating role of inflammatory factor using reliable routine check-up data from a cohort study. We found that lipid metabolism factor, blood pressure factor, obesity condition factor, glucose metabolism factor, renal function factor and lifestyle factor had diverse impact on development of dyslipidemia, directly and (or) indirectly, and inflammatory factor played a mediating role in the associations. Meanwhile, modeling the data with PLSPM indicated that lipid levels at baseline conferred the most important dimensional variable in the prediction of dyslipidemia, followed by obesity.

Our results illustrated that lipid-related markers at baseline is the most significant contributor in the prediction of dyslipidemia, which is consistent with previous studies showing that the corresponding lipid and lipoprotein levels in early life were the strongest predictors for dyslipidemia [9, 24]. Similarly, there is ample evidence that adverse lipid levels in childhood could persist over time, and progress to adult dyslipidemia and other cardiovascular diseases [25, 26]. Furthermore, preventive efforts aimed at dyslipidemia that start in early life could delay progression to adverse outcomes. Findings from clinical trials conducted in individuals starting with lipid level lower than current guideline targets showed that the risk of major vascular events was significantly reduced by $21 \%$ for each $1-\mathrm{mmol} / \mathrm{L}(38.7-\mathrm{mg} / \mathrm{dL})$ reduction in LDL-C [27]. Therefore, it is essential to monitor lipid levels and identify high-risk individuals as early as 
Table 2 Bootstrapping test of path coefficients in the partial least square path model

\begin{tabular}{|c|c|c|}
\hline Pathways & Path coefficient & t value \\
\hline Age $\rightarrow$ dyslipidemia & 0.03 & 6.71 \\
\hline Sex $\rightarrow$ dyslipidemia & -0.02 & 2.30 \\
\hline Lifestyle factor $\rightarrow$ dyslipidemia & 0.02 & 3.61 \\
\hline GMF $\rightarrow$ dyslipidemia & 0.03 & 6.31 \\
\hline OCF $\rightarrow$ dyslipidemia & 0.05 & 8.13 \\
\hline LMF $\rightarrow$ dyslipidemia & 0.67 & 138.37 \\
\hline $\mathrm{BPF} \rightarrow$ dyslipidemia & 0.01 & 1.97 \\
\hline RFF $\rightarrow$ dyslipidemia & 0.01 & 1.04 \\
\hline IF $\rightarrow$ dyslipidemia & 0.03 & 4.21 \\
\hline Lifestyle factor $\rightarrow \mathbb{I F}$ & 0.25 & 39.32 \\
\hline $\mathrm{GMF} \rightarrow \mathrm{IF}$ & 0.04 & 4.42 \\
\hline $\mathrm{OCF} \rightarrow \mathrm{IF}$ & 0.17 & 27.53 \\
\hline $\mathrm{LMF} \rightarrow \mathrm{IF}$ & 0.17 & 25.16 \\
\hline $\mathrm{BPF} \rightarrow \mathrm{IF}$ & 0.09 & 12.64 \\
\hline $\mathrm{RFF} \rightarrow \mathrm{IF}$ & 0.12 & 17.30 \\
\hline Lifestyle factor $\rightarrow$ IF $\rightarrow$ dyslipidemia & $0.25 \times 0.03$ & - \\
\hline $\mathrm{GMF} \rightarrow \mathrm{IF} \rightarrow$ dyslipidemia & $0.04 \times 0.03$ & - \\
\hline $\mathrm{OCF} \rightarrow \mathrm{IF} \rightarrow$ dyslipidemia & $0.17 \times 0.03$ & - \\
\hline $\mathrm{LMF} \rightarrow \mathrm{IF} \rightarrow$ dyslipidemia & $0.17 \times 0.03$ & - \\
\hline $\mathrm{BPF} \rightarrow \mathrm{IF} \rightarrow$ dyslipidemia & $0.09 \times 0.03$ & - \\
\hline $\mathrm{RFF} \rightarrow \mathrm{IF} \rightarrow$ dyslipidemia & $0.12 \times 0.03$ & - \\
\hline
\end{tabular}

possible, so that targeted interventions can be taken to prevent development of dyslipidemia and its related complications.

In regard to obesity condition factor measured by BMI, the current study demonstrated a risk effect on dyslipidemia, similar to the findings from previous studies [7, 28]. Accumulating evidence indicate that a state of chronic inflammation play a crucial role in the pathogenesis of obesity-related metabolic dysfunction [29-31]. We found that obesity condition factor had direct effect as well as indirect effect on dyslipidemia through inflammation. Pathway analysis suggested that obesity had greater effect than other biomarkers on inflammation as indicated by the higher path coefficient. Experimental studies have confirmed as adipose tissue expands, there is greater infiltration of macrophage and lymphocyte, which lead to an increase in chronic inflammation [32, 33]. A epidemiological study suggested that the levels of inflammatory biomarkers increased with elevation of obesity degree and a strong association between the biomarkers and BMI was demonstrated [34]. A recent study suggested that elevated plasma levels of inflammatory markers were positively associated with increased risk of dyslipidemia [14]. Inflammatory cell infiltration within adipose tissue may be involved in altering adipocyte lipid and cytokine production, which may in turn have downstream effects on lipid metabolism disorder [33, 35, 36]. Furthermore, the present study showed that lifestyle factor has an indirect effect on dyslipidemia through inflammation. Therefore, the findings provide valuable insights for strategies of dyslipidemia prevention. Controlling weight and changing lifestyle could be an effective way to decrease the levels of inflammatory biomarkers, and prevent the development of dyslipidemia.

Hypertension and dyslipidemia are two of modifiable risk factors for cardiovascular disease, and coexistence of the two factors is often observed in clinical settings, which exerts more than an additive impact on the vascular endothelium, resulting in atherosclerosis [37, 38]. It is reported that hypertensive individuals more frequently display lipid abnormities than normotensive ones [39, 40]. Our finding confirmed that elevated levels of blood pressure were associated with inflammation, which important pathway lead to dyslipidemia. The vasoconstriction that characterized a chronic hypertensive state may involve in the association between hypertension and increased risk of dyslipidemia [41]. It has been found that this hemodynamic phenomenon may address an adverse effect on lipid metabolism. For example, vasoconstriction may slow down the disposal of various components of the lipid profile in adipose and hepatic tissue [42]. Therefore, our findings suggested that hypertension combined with inflammatory markers may serve as potential intervention targets for the management of dyslipidemia.

A major strength of our study is that data from a large-scale of routine health check-up population based on a longitudinal study could provide convincing support of the hypothesized relationship. Second, we used pathway analysis to explore the effect of metabolic markers simultaneously as a system of multiple pathways on dyslipidemia, and the mediating role of inflammation on the associations. Elucidating the underlying mechanisms could increase our understanding of the potential biological pathways to dyslipidemia and provide a novel perspective for the research of dyslipidemia. Third, applying PLSPM method to construct structural equation model (SEM) in our study have some advantages in methodological feature. Compared to covariance-based SEM, PLSPM is a "soft modeling" approach requiring few distributional assumptions, in which variables can be numerical, ordinal or nominal, and no need for normality assumptions [20]. However, several limitations in this study need consideration. First, some of biomarkers in the model may not be perfect markers of the relevant metabolic pathways, because of the particularity of data collecting from routine health check-up population. For example, in our study NGC, MCC, WBC and GGT, widely available biomarkers in routine health check-up, were used to reflect inflammation other than $\mathrm{C}$ reaction 
protein, nor tumor necrosis factor- $\alpha$, interleukin-6. While the hematological parameters such as peripheral WBC count and GGT level may not be more robust, they have certain reference values for evaluating subclinical inflammation. Obesity factor was measured by BMI rather than waist circumference, which might be more sensitive indicator for dyslipidemia. Second, some potential confounders such as physical activity were not included in the model. These limitations may impose a modest constraint on the interpretation of these findings, but they should not substantively undermine the internal validity of the study.

\section{Conclusions}

In conclusion, the findings from our study informed that future management and treatment of dyslipidemia should take comprehensive intervention strategies into consideration, which is of great practical significance to choose monitoring, prevention and intervention strategies in general population. Given that inflammation mediates the associations between metabolic markers and dyslipidemia, combined preventive strategies on metabolic biomarkers and inflammation may be more effective in reducing the risk of dyslipidemia.

\section{Abbreviations}

BMl: Body mass index; BUN: Blood urea nitrogen; DBP: Diastolic blood pressure; FBG: Fasting blood glucose; GGT: y-glutamyltransferase; GMF: Glucose metabolism factor; HDL-C: High-density lipoprotein cholesterol; IF: Inflammatory factor; LDL-C: Low-density lipoprotein cholesterol; LMF: Lipid metabolism factor; MCC: Monocyte count; NGC: Neutrophile granulocyte; OCF: Obesity condition factor; PLSPM: Partial least squares path model; RFF: Renal function factor; SBP: Systolic blood pressure; SEM: Structural equation model; TC: Total cholesterol; TG: Triglyceride; WBC: White blood cell count
\end{abstract}

\section{Acknowledgments}

We would like to thank the participants for providing the information used in this study and for kindly making arrangement for data collection. We also received invaluable help from the members of the Center for Health Management of Shandong Provincial Qianfoshan Hospital.

\section{Authors' contributions}

FT and YL conceived the idea of the study; $Y L$ performed the analysis and prepared the drafts of manuscript; YL, LLX, YFL and FT participated in the discussions of data analyses and contributed to the manuscript revision; FT supervised the study and contributed the critical revision. All authors have read and approved the final manuscript.

\section{Funding}

The study was supported by National Natural Science Foundation of China (71804093), Shandong Provincial Natural Science Foundation (ZR2015HL102) and Shandong Provincial Medical and Health Science and Technology Development Project (2016WS0478).

\section{Availability of data and materials}

The datasets used in the current study are available from the corresponding author upon reasonable request.

\section{Ethics approval and consent to participate}

This study was approved by the Ethics Committee of Shandong provincial Qianfoshan Hospital. Written informed consent was obtained from all subjects.
Consent for publication

Not applicable.

\section{Competing interests}

The authors declare that they have no competing interests.

\section{Author details}

${ }^{1}$ Center for Data Science in Health and Medicine, Shandong Provincial Qianfoshan Hospital, The First Affiliated Hospital of Shandong First Medical University, Jingshi Road 16766, Jinan 250014, China. ${ }^{2}$ Shandong Provincial Qianfoshan Hospital Affiliated to Shandong University, Jinan, China. ${ }^{3}$ Department of Endocrinology, Zhangqiu District Hospital of Traditional Chinese Medicine, Jinan, China.

Received: 14 January 2019 Accepted: 22 August 2019

Published online: 31 August 2019

\section{References}

1. Kavey RE, Daniels SR, Lauer RM, Atkins DL, Hayman LL, Taubert K. American Heart Association guidelines for primary prevention of atherosclerotic cardiovascular disease beginning in childhood. Circulation. 2003;107(11):1562-6.

2. Joint committee for guideline revision. 2016 Chinese guidelines for the management of dyslipidemia in adults. J Geriatr Cardiol. 2018;15(1):1-29.

3. Laslett $\amalg$, Jr PA, lii BAC, Jr JPD, Saldivar F, Wilson SR, Poe C, Hart M. The worldwide environment of cardiovascular disease: prevalence, diagnosis, therapy, and policy issues: a report from the American College of Cardiology. J Am Coll Cardiol. 2012;60(25):S1-S49.

4. Pan L, Yang Z, Wu Y, Yin RX, Liao Y, Wang J, Gao B, Zhang L. The prevalence, awareness, treatment and control of dyslipidemia among adults in China. Atherosclerosis. 2016;248:2-9.

5. Wu Y, Huxley R, Li L, Anna V, Xie G, Yao C, Woodward M, Li X, Chalmers J, Gao R. Prevalence, awareness, treatment, and control of hypertension in China: data from the China National Nutrition and health survey 2002. Circulation. 2008;118(25):2679-86.

6. Forouzanfar MH, Alexander L, Anderson HR, Bachman VF, Biryukov S, Brauer M, Burnett R, Casey D, Coates MM, Cohen A, et al. Global, regional, and national comparative risk assessment of 79 behavioural, environmental and occupational, and metabolic risks or clusters of risks in 188 countries, 1990 2013: a systematic analysis for the global burden of disease study 2013. Lancet. 2015;386(10010):2287-323.

7. Bayram F, Kocer D, Gundogan K, Kaya A, Demir O, Coskun R, Sabuncu T, Karaman A, Cesur M, Rizzo M, et al. Prevalence of dyslipidemia and associated risk factors in Turkish adults. J Clin Lipidol. 2014;8(2):206-16.

8. Wu JY, Duan XY, Li L, Dai F, Li YY, Li XJ, Fan JG. Dyslipidemia in Shanghai. China Prev Med. 2010;51(5):412-5.

9. Nuotio J, Pitkänen N, Magnussen CG, Buscot MJ, Venäläinen MS, Elo LL, Jokinen E, Laitinen T, Taittonen L, Hutrikähönen N, et al. Prediction of adult dyslipidemia using genetic and childhood clinical risk factors: the cardiovascular risk in young Finns study. Circ Cardiovasc Genet. 2017;10(3): e001604.

10. Wang CJ, Li YQ, Wang L, Li LL, Guo YR, Zhang LY, Zhang MX, Bie RH. Development and evaluation of a simple and effective prediction approach for identifying those at high risk of dyslipidemia in rural adult residents. PLoS One. 2012;7(8):e43834.

11. Joel N, Mervi O, Magnussen CG, Viikari JSA, Nina HKHN, Antti J, Russell T, Sabin MA, Daniels SR, Raitakari OT, et al. Adult dyslipidemia prediction is improved by repeated measurements in childhood and young adulthood. The cardiovascular risk in young Finns study. Atherosclerosis. 2015:239(2):350-7.

12. Yang X, Xu C, Wang Y, Cao C, Tao Q, Zhan S, Sun F. Risk prediction model of dyslipidaemia over a 5-year period based on the Taiwan MJ health check-up longitudinal database. Lipids Health Dis. 2018;17(1):259.

13. Dongway AC, Faggad AS, Zaki HY, Abdalla BE. C-reactive protein is associated with low-density lipoprotein cholesterol and obesity in type 2 diabetic Sudanese. Diabetes Metab Syndr Obes. 2015;8:427-35.

14. Tang L, Peng $H, X u T$, Wang A, Wang G, Tong W, Zhang Y. Association of biomarkers of inflammation with dyslipidemia and its components among Mongolians in China. PLoS One. 2014;9(2):e89023.

15. Kim MH, Kim HN, Choi WS. The association between subclinical inflammation and abnormal glucose and lipid metabolism in normal-weight Korean individuals. Nutr Metab Cardiovasc Dis. 2018;28(11):1106-13. 
16. Madjid M, Fatemi O. Components of the complete blood count as risk predictors for coronary heart disease: in-depth review and update. Tex Heart Inst J. 2013;40(1):17-29.

17. Lee YJ, Kim JK, Lee JH, Lee HR, Kang DR, Shim JY. Association of serum gamma-glutamyltransferase with C-reactive protein levels and white blood cell count in Korean adults. Clin Chem Lab Med. 2008;46(10):1410-5.

18. Correia-Costa L, Santos AC, Severo M, Guerra A, Schaefer F, Afonso AC, Barros $\mathrm{H}$, Azevedo A. Sex-specific mediating role of insulin resistance and inflammation in the effect of adiposity on blood pressure of prepubertal children. PLoS One. 2015;10(6):e0132097.

19. Juonala M, Singh GR, Davison B, Van SK, Skilton MR, Sabin MA, Cheung M, Sayers S, Burgner DP. Childhood metabolic syndrome, inflammation and carotid intima-media thickness. The aboriginal birth cohort study. Int J Cardiol. 2015;203:32-6.

20. Tenenhaus M, Vinzi VE, Chatelinc YM, Laurob C. PLS path modeling. Comput Stat Data Anal. 2005;48(1):159-205.

21. Vinzi VE, Trinchera L, Amato S. PLS path modeling: from foundations to recent developments and open issues for model assessment and improvement. In: Handbook of partial least squares; 2010. p. 47-82.

22. Henseler J, Fassott G. Testing moderating effects in PLS path models: an illustration of available procedures. In: Handbook of partial least squares: 2010. p. 713-35

23. Ketchen DJ. A primer on partial least squares structural equation modeling Long Range Plan. 2013;46(1):184-5.

24. Nicklas TA, von Duvillard SP, Berenson GS. Tracking of serum lipids and lipoproteins from childhood to dyslipidemia in adults: the Bogalusa heart study. Int J Sports Med. 2002;23(S1):39-43.

25. Lozano P, Henrikson NB, Morrison CC, Dunn J, Nguyen M, Blasi PR, Whitlock EP. Lipid screening in childhood and adolescence for detection of multifactorial dyslipidemia: evidence report and systematic review for the US preventive services task force. JAMA. 2016;316(6):634-44.

26. Srinivasan SR, Frontini MG, Jihua X, Berenson GS. Utility of childhood non-highdensity lipoprotein cholesterol levels in predicting adult dyslipidemia and other cardiovascular risks: the Bogalusa heart study. Pediatrics. 2006;118(1):201-6.

27. Sabatine MS, Wiviott SD, Im K, Murphy SA, Giugliano RP. Efficacy and safety of further lowering of low-density lipoprotein cholesterol in patients starting with very low levels: a meta-analysis. JAMA Cardiol. 2018;3(9):823-8.

28. Bekele S, Yohannes T, Mohammed AE. Dyslipidemia and associated factors among diabetic patients attending Durame general Hospital in Southern Nations, nationalities, and people's region. Diabetes Metab Syndr Obes. 2017;10:265-71.

29. Fuentes E, Fuentes F, Vilahur G, Badimon L, Palomo I. Mechanisms of chronic state of inflammation as mediators that link obese adipose tissue and metabolic syndrome. Mediators Inflamm. 2013;2013(3):136584.

30. Reho JJ, Rahmouni K. Oxidative and inflammatory signals in obesityassociated vascular abnormalities. Clin Sci (Lond). 2017;131(14):1689-700.

31. Carey NL, Alan RS. Inflammatory links between obesity and metabolic disease. J Clin Invest. 2011;121(6):2111-7.

32. Dam V, Sikder T, Santosa S. From neutrophils to macrophages: differences in regional adipose tissue depots. Obes Rev. 2016;17(1):1-17.

33. Gutierrez DA, Puglisi MJ, Hasty AH. Impact of increased adipose tissue mass on inflammation, insulin resistance, and dyslipidemia. Curr Diab Rep. 2009;9(1):26-32.

34. Piva SJ, Tatsch E, De Carvalho JA, Bochi GV, Kober H, Duarte T, Duarte MM, da Cruz IB, Moretto MB, Moresco RN. Assessment of inflammatory and oxidative biomarkers in obesity and their associations with body mass index. Inflammation. 2013;36(1):226-31.

35. Jung UJ, Choi MS. Obesity and its metabolic complications: the role of adipokines and the relationship between obesity, inflammation, insulin resistance, dyslipidemia and nonalcoholic fatty liver disease. Int J Mol Sci. 2014;15(4):6184-223.

36. Bays HE, Toth PP, Kris-Etherton PM, Abate N, Aronne LJ, Brown W, Gonzalez-Campoy JM, Jones SR, Kumar R, Forge RL. Obesity, adiposity, and dyslipidemia: a consensus statement from the National Lipid Association. J Clin Lipidol. 2013;7(4):304-83.

37. Dalal JJ, Padmanabhan TNC, Jain P, Patil S, Vasnawala H, Gulati A LIPITENSION: interplay between dyslipidemia and hypertension. Indian J Endocrinol Metab. 2012;16(2):240-5.

38. Wong ND, Lopez V, Tang S, Williams GR. Prevalence, treatment, and control of combined hypertension and hypercholesterolemia in the United States. Am J Cardiol. 2006;98(2):204-8.
39. Gebrie A, Gnanasekaran N, Menon M, Sisay M, Zegeye A. Evaluation of lipid profiles and hematological parameters in hypertensive patients: laboratorybased cross-sectional study. SAGE Open Med. 2018;6:2050312118756663.

40. Mancia G, Facchetti R, Bombelli M, Polo Friz H, Grassi G, Giannattasio C, Sega R. Relationship of office, home, and ambulatory blood pressure to blood glucose and lipid variables in the PAMELA population. Hypertension. 2005;45(6):1072-7.

41. Oh J, Lee CJ, Kim IC, Lee SH, Kang SM, Choi D, Park S, Kario K. Association of morning hypertension subtype with vascular target organ damage and central hemodynamics. J Am Heart Assoc. 2017;6(2):e005424.

42. Nonogaki K. New insights into sympathetic regulation of glucose and fat metabolism. Diabetologia. 2000;43(5):533-49.

\section{Publisher's Note}

Springer Nature remains neutral with regard to jurisdictional claims in published maps and institutional affiliations.
Ready to submit your research? Choose BMC and benefit from:

- fast, convenient online submission

- thorough peer review by experienced researchers in your field

- rapid publication on acceptance

- support for research data, including large and complex data types

- gold Open Access which fosters wider collaboration and increased citations

- maximum visibility for your research: over $100 \mathrm{M}$ website views per year

At BMC, research is always in progress.

Learn more biomedcentral.com/submissions 